\title{
Antihypertensive effect of aqueous polyphenol extracts of Amaranthusviridis and Telfairiaoccidentalis leaves in spontaneously hypertensive rats
}

\author{
Olayinka A. Olarewaju, Adeola M. Alashi and Rotimi E. Aluko* \\ Department of Food and Human Nutritional Sciences, University of Manitoba, Winnipeg, Canada R3T 2N2 \\ ${ }^{*}$ Corresponding author: Dr. Rotimi Aluko, Department of Food and Human Nutritional Sciences, University of Manitoba, Winnipeg, \\ Canada R3T 2N2. E-mail: rotimi.aluko@umanitoba.ca \\ DOI: $10.31665 /$ JFB.2018.1135 \\ Received: December 12, 2017; Revised received \& accepted: February 9, 2018 \\ Citation: Olarewaju, O.A., Alashi, A.M., and Aluko, R.E. (2018). Antihypertensive effect of aqueous polyphenol extracts of Amaranthus- \\ viridis and Telfairiaoccidentalis leaves in spontaneously hypertensive rats. J. Food Bioact. 1: 166-173.
}

\begin{abstract}
The antihypertensive effects of aqueous polyphenol-rich extracts of Amaranthusviridis (AV) and Telfairiaoccidentalis (TO) leaves in spontaneously hypertensive rats (SHR) were investigated. The dried vegetable leaves were extracted using 1:20 (leaves:water, w/v) ratio for $4 \mathrm{~h}$ at $60^{\circ} \mathrm{C}$. Results showed significantly $(\mathrm{P}<0.05)$ higher polyphenol contents in TO extracts (80-88 mg gallic acid equivalents, GAE/100 mg) when compared with the AV (62-67 mg GAE/100 mg). Caffeic acid, rutin and myricetin were the main polyphenols found in the extracts. The TO extracts had significantly $(P<0.05)$ higher in vitro inhibition of angiotensin I-converting enzyme (ACE) activity while AV extracts had better renin inhibition. Oral administration (100 mg/kg body weight) to SHR led to significant $(P<0.05)$ reductions in systolic blood pressure for the AV $(-39 \mathrm{mmHg}$ after $8 \mathrm{~h})$ and TO $(-24 \mathrm{mmHg}$ after 4 and $8 \mathrm{~h}$ ). The vegetable extracts also produced significant $(\mathrm{P}<0.05)$ reductions in diastolic blood pressure, mean arterial blood pressure and heart rate when compared to the untreated rats. Thus both the AV and TO leaf extracts have the potential to be used as antihypertensive agents, especially the AV, which produced persistent long-lasting effect over a $24 \mathrm{~h}$ period.
\end{abstract}

Keywords: Renin; Angiotensin converting enzyme; Antihypertensive properties; Spontaneously hypertensive rats; Blood pressure; Polyphenol extract.

\section{Introduction}

Hypertension is responsible for 9.4 million deaths worldwide, which is equivalent to about $18 \%$ of all annual deaths (WHO, 2013). Hypertension is also known as high blood pressure and is a chronic disease that afflicts millions of people worldwide. High blood pressure occurs when the systolic blood pressure is above $140 \mathrm{mmHg}$ and the diastolic blood pressure is above $90 \mathrm{mmHg}$ (Pickering et al., 2005). Hypertension can also lead to other negative health outcomes such as stroke, coronary heart disease, physical disability and kidney dysfunction if left untreated (Chen et al., 2009). However, the disease intensity of hypertension can be ameliorated with the use of different drugs such as diuretics, angioten- sin converting enzyme (ACE) inhibitors, calcium channel blockers, renin inhibitors and vasodilators (nitrates). ACE and renin are targets for hypertension therapies because they form a key component of the renin-angiotensin system (RAS) that controls mammalian blood pressure. When there is a fall in blood pressure, rennin breaks down plasma angiotensinogen to give rise to angiotensin I, which is then converted to angiotensin II (a vasoconstrictor) by the action of ACE (Chen et al., 2009; Girgih et al., 2011). However, in disease conditions there is excessive formation of angiotensin II, which leads to insufficient relaxation of blood vessels and hence high blood pressure develops. Therefore, inhibition of ACE and renin activities is important in lowering plasma level of angiotensin II, which facilitates blood pressure reductions. However, the use 
of antihypertensive drugs has been associated with negative side effects such as rashes, edema, dry coughing and erectile dysfunction (Abassiet al., 2009; Blumentalset al., 2003; Fogariet al., 2001; Gunkelet al., 1996; Tenenbaumet al., 2000). Therefore, natural alternative therapies such as peptides (Aluko, 2015) and polyphenols (Hellstrom et al., 2010; Kivimaki et al., 2013; Shaw et al., 2017) with potential fewer negative side effects have been suggested as effective antihypertensive agents.

Traditionally, green leafy vegetables have been used as spice in foods or for culinary purposes while vegetable extracts have formed part of folk medicine agents used to treat or manage different human diseases (Farombi and Owoeye, 2011). Moreover, consumption of vegetable-rich diets has been reported to improve or attenuate some human diseases due to their antioxidant properties (Oboh and Rocha, 2007). This is because plants are rich sources of phenolic compounds, which have anti-diabetic, anti-carcinogenic, anti-inflammatory, anti-hypertensive and hepatoprotective properties (Farombi and Owoeye, 2011).

Amaranthusviridis (AV) and Telfariaoccidentalis (TO) leaves are common vegetables found in West Africa. The leaf extracts of these vegetables have been reported to have various pharmacological effects in addition to antimicrobial, antidiabetic, and antihyperlipidemic activities (Nwanna et al., 2016; Oboh et al., 2006). AV contains betalains and saponins (Hussain et al., 2008), while the leaves of TO are rich in vitamins and potassium (Oboh et al., 2006). These leafy vegetables are also rich in polyphenols (gallic acid, chlorogenic acid, quercetin, kaempferol, caffeic acid, rutin, myricetin), which are a group of compounds that have been demonstrated to inhibit ACE activity and lead to blood pressure reductions (Dong et al., 2011; Kivimaki et al., 2013; Shaw et al., 2017). The vegetables are cheap, readily available and their consumption may provide health benefits by functioning as antihypertensive agents. However, there is scant information on the ability of polyphenolic extracts from these vegetables (AV and $\mathrm{TO}$ ) to inhibit $\mathrm{ACE}$ and renin activities or reduce blood pressure. Therefore, the aim of this work was to determine the inhibition of in vitro activities of ACE and renin by aqueous extracts of AV and TO leaves. Ability of the leaf polyphenolic extracts to reduce blood pressure and heart rate was then measured after oral administration to spontaneously hypertensive rats (SHR).

\section{Materials and methods}

\subsection{Materials}

Ground leaf powders of the two vegetables were obtained from vegetable plants cultivated at the Teaching and Research Farm of the Obafemi Awolowo University, Ile-Ife, Nigeria. Urea fertilizer doses $(0,20,40,60$ and $80 \mathrm{kgN} / \mathrm{ha})$ were applied to the vegetables on plot by plot basis in randomized complete block design. Fertilizer was applied to each plot either at planting (T1) or one week after seedling emergence (T2) to obtain the following samples: 0T1, 0T2, 20T1, 20T2, 40T1, 40T2, 60T1, 60T2, 80T1, and 80T2. Samples were harvested by plucking, cut into small pieces, dried in a hot air cabinet at $\sim 60{ }^{\circ} \mathrm{C}$ for $8 \mathrm{~h}$ and then milled to fine powder using a MarlexExcella dry mill (Marlex Appliances PVT, Daman, India). The ground powders were then stored at -20 ${ }^{\circ} \mathrm{C}$ prior to analysis. N-(3-[2-furyl]acryloyl)-phenylalanylglycylglycine (FAPGG), and ACE from rabbit lung (E.C.3.4.15.1) were purchased from Sigma-Aldrich (St. Louis, MO, USA). A Human Recombinant Renin Inhibitor Screening Assay Kit was purchased from Cayman Chemicals (Ann Arbor, MI, USA). All other rea- gents are of analytical grade and purchased from Fisher Scientific (Oakville, ON, Canada).

\subsection{Polyphenol extraction}

Extraction of the free water-soluble polyphenols was carried out according to the method of Alu'datt et al. (2010) with slight modifications. It should be noted that this method does not measure the content of bound polyphenols. Samples were extracted using distilled water at ratios of 1:20 (w/v) ground leaf powder to water for $2 \mathrm{~h}$ in a beaker with continuous stirring at $60^{\circ} \mathrm{C}$. The extract was centrifuged $\left(10000 \times \mathrm{g}, 30 \mathrm{~min}, 24^{\circ} \mathrm{C}\right)$, the supernatant saved while the residue was re-extracted with 20 volumes of water under same conditions as the first extraction. After the second centrifugation, the two supernatants were combined, filtered through cheese cloth, and concentrated under vacuum using a rotatory evaporator at $60{ }^{\circ} \mathrm{C}$. The concentrated extracts were freeze dried and stored at $-20{ }^{\circ} \mathrm{C}$ for further analysis. The total polyphenolic content (TPC) of each extract was determined using the Folin-Ciocalteu method (Hoff \& Singleton, 1977), which was modified as follows. A standard calibration curve was prepared using $25-350 \mu \mathrm{g} / \mathrm{mL}$ gallic acid concentration in $50 \%(\mathrm{v} / \mathrm{v})$ aqueous methanol. The polyphenol extracts were also diluted with the $50 \%$ methanol to $600-1400 \mu \mathrm{g} /$ $\mathrm{mL}$. A $250 \mu \mathrm{L}$ aliquot of Folin-Ciocalteu reagent was added to 250 $\mu \mathrm{L}$ of gallic acid solution or the diluted sample and then mixed on a vortex. After standing in the dark at room temperature for 5 min, $0.5 \mathrm{~mL}$ of $20 \%(\mathrm{w} / \mathrm{v})$ sodium carbonate solution was added followed by $4 \mathrm{~mL}$ of double distilled water. The contents were vortexed and incubated again in the dark for $1 \mathrm{~h}$. Intensity of the green colour was then measured at $725 \mathrm{~nm}$ using an Ultospec UV-visible spectrophotometer (GE Healthcare, Montreal, PQ, Canada). TPC was expressed as milligrams gallic acid equivalents (GAE) per 100 mg dry leaf extract (mg GAE/100 mg).

\subsection{Estimation of main polyphenolic compounds}

The major polyphenol constituents of the AV and TO leaf extracts were quantified using the Varian 900-LC series analytical HPLC (Phenomenex Inc., Torrance, CA, USA) using a Phenomenex C18 HPLC column $(250 \mathrm{~mm} \times 4.6 \mathrm{~mm}, 5 \mu \mathrm{m})$ heated to $30{ }^{\circ} \mathrm{C}$. The mobile phases used were $1 \%$ acetic acid (solvent $\mathrm{A}$ ) and methanol (solvent B) with the following gradients $95 \%$ A to $5 \%$ B for 35 min; $80 \%$ A to $20 \%$ B for $15 \mathrm{~min} ; 40 \%$ A to $60 \%$ B for $10 \mathrm{~min}$ and $70 \% \mathrm{~A}$ and $30 \% \mathrm{~B}$ for $15 \mathrm{~min}$. The flow rate was fixed at $1.0 \mathrm{~mL} /$ min and standards (caffeic acid, catechin, gallic acid, rutin, myricetin and quercetin) and samples were injected using $20 \mu \mathrm{L}$ solutions while detection wavelengths were at 280 and $320 \mathrm{~nm}$. The level of each polyphenol was estimated using the calibration curve generated from the linear plot of elution time versus peak area of each standard polyphenol compound and the results expressed as $\mathrm{mg} / \mathrm{g}$ of dry leaf extracts.

\subsection{Renin inhibition assay}

In vitro inhibition of human recombinant renin activity was conducted according to the method described by Li and Aluko (2010) using the Renin Inhibitor Screening Assay Kit. Prior to the assay, renin buffer was diluted with $50 \mathrm{mM}$ Tris- $\mathrm{HCl}(\mathrm{pH}$ 8.0) that contained $100 \mathrm{mM} \mathrm{NaCl}$. The renin protein solution was diluted 20 times with assay buffer before use, and the assay buffer was prewarmed to $37^{\circ} \mathrm{C}$ before the reaction was initiated in a fluoromet- 
Table 1. Total phenoliccontent (mggallic acid equivalent/g) of Amaranthusviridis (AV) and Telfairiaoccidentalis (TO) leaf extracts

\begin{tabular}{lll}
\hline Samples & AV & TO \\
\hline 0T1 & $462.09 \pm 1.42^{\mathrm{a}, \mathrm{b}}$ & $597.57 \pm 1.50^{\mathrm{f}}$ \\
0T2 & $466.18 \pm 2.45^{\mathrm{b}, \mathrm{c}}$ & $581.94 \pm 3.97^{\mathrm{c}, \mathrm{d}}$ \\
20T1 & $460.46 \pm 2.83^{\mathrm{a}}$ & $585.42 \pm 0.00^{\mathrm{d}}$ \\
20T2 & $469.44 \pm 5.10^{\mathrm{c}}$ & $590.63 \pm 2.60^{\mathrm{e}}$ \\
40T1 & $462.91 \pm 1.42^{\mathrm{a}, \mathrm{b}}$ & $573.26 \pm 1.50^{\mathrm{b}}$ \\
40T2 & $460.46 \pm 3.74^{\mathrm{a}}$ & $582.81 \pm 2.60^{\mathrm{c}, \mathrm{d}}$ \\
60T1 & $462.09 \pm 1.42^{\mathrm{a}, \mathrm{b}}$ & $578.47 \pm 1.50^{\mathrm{c}}$ \\
60T2 & $462.91 \pm 1.42^{\mathrm{a}, \mathrm{b}}$ & $557.64 \pm 6.01^{\mathrm{a}}$ \\
$80 \mathrm{~T} 1$ & $461.27 \pm 2.45^{\mathrm{a}, \mathrm{b}}$ & $592.36 \pm 1.50^{\mathrm{e}}$ \\
80T2 & $463.73 \pm 0.00^{\mathrm{a}, \mathrm{b}}$ & $611.46 \pm 2.60^{\mathrm{g}}$ \\
\hline
\end{tabular}

*Mean + standard deviation. For each column, values with different letters are sig nificantly different $(P<0.05)$.

ric microplate reader (Spectra MAX Gemini, Molecular Devices, Sunnyvale, CA, USA) maintained at $37^{\circ} \mathrm{C}$. Before the reaction, (1) $20 \mu \mathrm{L}$ substrate, $160 \mu \mathrm{L}$ assay buffer, and $10 \mu \mathrm{L}$ Milli-Q water were added to the background wells; (2) $20 \mu \mathrm{L}$ substrate, $150 \mu \mathrm{L}$ assay buffer, and $10 \mu \mathrm{L}$ Milli- $\mathrm{Q}$ water were added to the control wells; and (3) $20 \mu \mathrm{L}$ substrate, $150 \mu \mathrm{L}$ assay buffer, and $10 \mu \mathrm{L}$ sample $(0.25 \mathrm{mg}$ GAE $/ \mathrm{mL}$ final assay concentration) were added to the inhibitor wells. The reaction was initiated by adding $10 \mu \mathrm{L}$ renin to the control and sample wells. The microplate was shaken for 10 $\mathrm{s}$ to mix and incubated at $37{ }^{\circ} \mathrm{C}$ for $15 \mathrm{~min}$, and the fluorescence intensity (FI) was then recorded using an excitation and emission wavelengths of 340 and $490 \mathrm{~nm}$, respectively. The percentage inhibition was calculated as follows:

$$
\begin{aligned}
& \text { Inhibition }(\%)= \\
& \frac{\text { FI of control wells }- \text { FI of sample wells }}{\text { FI of control wells }} \times 100
\end{aligned}
$$

\subsection{ACE inhibition assay}

Ability of the polyphenolic extracts to inhibit in vitro activity of ACE was measured according to a spectrophotometric method using synthetic N-[3-(2-Furyl)acryloyl]-L-phenylalanyl-glycylglycine (FAPGG) as the substrate (Holmquist et al., 1979). Briefly, $20 \mu \mathrm{L}$ of sample dissolved in $50 \mathrm{mM}$ Tris- $\mathrm{HCl}$ buffer containing $0.3 \mathrm{M} \mathrm{NaCl}, \mathrm{pH} 7.5$ (0.5 mg GAE/mL final assay concentration) was mixed with $10 \mu \mathrm{L}$ of ACE ( $20 \mathrm{mU}$ final reaction activity) and $170 \mu \mathrm{L}$ of $0.5 \mathrm{mM}$ FAPGG dissolved in the same buffer in a 96well microplate. The rate of decrease in absorbance at $345 \mathrm{~nm}$ was recorded for $30 \mathrm{~min}$ at $37^{\circ} \mathrm{C}$ using a microplate reader. The buffer was used instead of sample solutions in the blank experiment.

\subsection{Blood pressure measurement}

SHRsat 6 weeks were purchased from Charles River Laboratories (Montreal, PQ, Canada) and implanted with telemetry sensors after acclimatization (under 12-h day and night cycle at $21{ }^{\circ} \mathrm{C}$ ) for 2 weeks. Rats were provided with ad libitum access to regular chow feed and tap water. Telemetry sensors were surgically im- planted into the rats according to our previously described protocols (O'Keeffeet al., 2017). After a 2-week recovery from the surgery, the groups were assigned 4 rats each followed by oral administration $(1 \mathrm{~mL})$ of test agents, which were all dissolved in phosphate buffered saline (PBS): PBS only (negative control); 20 $\mathrm{mg} / \mathrm{kg}$ body wt captopril (antihypertensive drug as a positive control); and $100 \mathrm{mg} \mathrm{GAE} / \mathrm{kg}$ body wt polyphenol extract. Real time changes in heart functions were measured as systolic blood pressure (SBP), diastolic blood pressure (DBP), mean arterial pressure (MAP) and heart rates (HR) in a quiet room with each rat cage placed on the respective receiver (Model RPC-1, DSI instruments, St. Paul, MN, USA). All the rat protocols were approved by the University of Manitoba Animal Care Committee. Data were recorded continuously at $10 \mathrm{~min}$ intervals for $24 \mathrm{~h}$ using the Ponemah 6.1 data acquisition software (DSI instruments). The system was linked to an APR-1 atmospheric-pressure monitor (DSI instruments), which normalized the transmitted pressure values to produce blood pressure signals independent of changes in atmospheric pressure. Results are reported as the SBP, DBP, MAP and HR values at 2, 4, 6, 8, 12 and $24 \mathrm{~h}$ minus their baseline measurements at time zero.

\subsection{Statistical analysis}

Analyses were conducted in replicates as indicated above and analyzed by 3-way analysis of variance (ANOVA) for in vitro assay using a model that included vegetable variety (VV), fertilizer dose (FD) and fertilizer application time (FT) as fixed variables and one-way analysis of variance for in vivo assay. Data were reported as mean \pm standard deviation. Statistical significance of differences was evaluated by Duncan's multiple range test $(\mathrm{P}<0.05)$ using the IBM SPSS Statistical package (version 24).

\section{Results and discussion}

\subsection{TPC, polyphenol contents and the inhibitions of in vitro ACE and renin activities}

In this work, water extraction was used because initial trials with solvents or mixtures of solvents and water yielded insoluble extracts after freeze-drying. In contrast, the freeze-dried water extracts were readily solubilized by the aqueous reagents used for various analytical and in vivo determinations. The TPC of the samples are shown in Table 1 and the data indicate that the extracts were mainly composed of polyphenols with values up to 469 and $611 \mathrm{mg} \mathrm{GAE} / \mathrm{g}$ of dried extracts for $\mathrm{AV}$ and TO, respectively. However, all the TO extracts contained significantly $(\mathrm{P}<0.05)$ higher polyphenol contents than similar AV extracts. The results suggest the presence of more free water-soluble polyphenols in the TO leaves than the AV leaves. Table 2 shows that caffeic acid, rutin and myricetin were the main polyphenols detected in the leaf extracts. Caffeic acid was the polyphenol in the TO extracts while rutin and caffeic acid were present in the AV extracts at similar levels. Myricetin was the least abundant in both extracts while the levels of caffeic acid was higher in the TO extracts than the AV extracts.

Since there were differences in the TPC values, samples were equalized to contain same amount of polyphenols (GAE) for all the in vitro and in vivo experiments. With the exception of TO20T1 and irrespective of the fertilizer dosage and time of application, the TO extracts had significantly higher $(\mathrm{P}<0.05)$ ACE-inhibitory 
Table 2. Estimated phenolic compounds in Amaranthusviridis (AV) and Telfairiaoccidentalis (TO) leaf aqueous extract (mg/g dry weight)*

\begin{tabular}{|c|c|c|c|c|c|c|}
\hline \multirow{2}{*}{ Samples } & \multicolumn{2}{|c|}{ Caffeic acid } & \multicolumn{2}{|c|}{ Rutin } & \multicolumn{2}{|c|}{ Myricetin } \\
\hline & AV & TO & AV & TO & AV & TO \\
\hline 0T1 & $1.57 \pm 0.08$ & $6.22 \pm 0.04$ & $1.55 \pm 1.34$ & $0.05 \pm 0.00$ & $0.17 \pm 0.15$ & $0.01 \pm 0.00$ \\
\hline OT2 & $1.55 \pm 0.04$ & $4.19 \pm 0.02$ & $1.24 \pm 0.92$ & $0.01 \pm 0.00$ & $0.17 \pm 0.05$ & $0.01 \pm 0.00$ \\
\hline 20T1 & $1.70 \pm 0.04$ & $5.23 \pm 0.11$ & $1.18 \pm 0.15$ & $0.06 \pm 0.00$ & $0.15 \pm 0.01$ & $0.01 \pm 0.00$ \\
\hline $20 T 2$ & $1.62 \pm 0.01$ & $3.64 \pm 0.26$ & $0.94 \pm 0.04$ & $0.05 \pm 0.02$ & $0.13 \pm 0.01$ & $0.01 \pm 0.00$ \\
\hline 40T1 & $0.30 \pm 0.04$ & $7.33 \pm 0.02$ & $0.33 \pm 0.02$ & $0.07 \pm 0.00$ & $0.11 \pm 0.01$ & $0.01 \pm 0.00$ \\
\hline $40 T 2$ & $1.14 \pm 0.94$ & $6.66 \pm 0.43$ & $1.16 \pm 0.77$ & $0.32 \pm 0.14$ & $0.14 \pm 0.03$ & $0.01 \pm 0.00$ \\
\hline 60T1 & $1.62 \pm 0.05$ & $7.73 \pm 0.10$ & $1.04 \pm 0.54$ & $0.07 \pm 0.00$ & $0.17 \pm 0.02$ & $0.01 \pm 0.00$ \\
\hline $60 T 2$ & $1.54 \pm 0.02$ & $5.24 \pm 0.29$ & $0.94 \pm 0.05$ & $0.03 \pm 0.00$ & $0.17 \pm 0.02$ & $0.01 \pm 0.00$ \\
\hline 80T1 & $1.49 \pm 0.02$ & $4.64 \pm 0.15$ & $0.89 \pm 0.01$ & $0.03 \pm 0.00$ & $0.08 \pm 0.06$ & $0.00 \pm 0.00$ \\
\hline $80 T 2$ & $1.44 \pm 0.06$ & $6.88 \pm 0.02$ & $0.80 \pm 0.07$ & $0.06 \pm 0.00$ & $0.05 \pm 0.00$ & $0.01 \pm 0.00$ \\
\hline
\end{tabular}

$* 0,20,40,60,80$ indicate amount of applied urea fertilizer (kg/ha); T1 and T2 represents fertilizer applied at planting and 1 week after seedling emergence, respectively.

activities than the AV extracts (Fig. 1). In addition to variety effect, the fertilizer dose also had a significant effect on ACE inhibition by the polyphenol extracts (Table 2). However, fertilizer application time (FT) had no significant effect on ACE inhibition. The results are consistent with previous reports that showed ACE activity inhibition by phenolic-rich plant extracts (Lacaille-Dubois et al., 2001; Oboh et al., 2013; Shaw et al., 2017; Wagner and Elbl, 1992).ACE inhibitors as treatment for hypertension has achieved great feat in the field of medicine. This is because these inhibitors promote endothelia function and increased activity of bradykinin, which is a vasodilator (Ghiadoni et al. 2003). Since the same polyphenol concentration was used, the better ACE-inhibitory activity of TO suggests that the higher contents of caffeic acid may be have been a contributing factor.

Fig. 2 shows that all the AV extracts inhibited renin activity while only the TO extracts from the $20-60 \mathrm{~kg} \mathrm{~N}$ fertilizer application had inhibitory activities. This trend of renin inhibition is opposite that of ACE-inhibition where TO extracts had superior effects than the AV extracts. The results obtained in this work

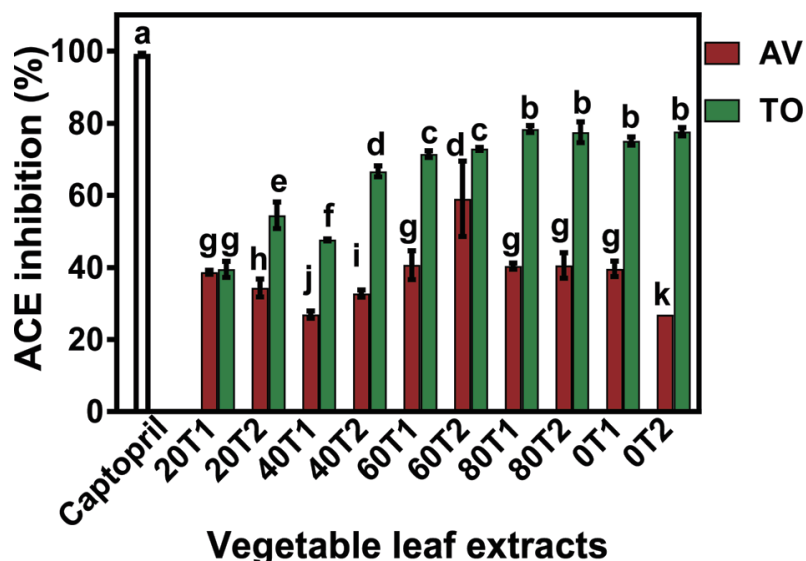

Figure 1. ACE-inhibitory activity of Amaranthusviridis (AV) and Telfariaoccidentalis (TO) polyphenol concentrates at $0.5 \mathrm{mg} / \mathrm{mL}$. 0-80 represent applied nitrogen fertilizer at planting (T1) or 1 week after seedling emergence (T2). Bars with different letters have significantly different $(P<0.05)$ mean values. agree with those reported by Udenigwe et al. (2009) and Malomo et al. (2015) who found no direct correlation between ACE and renin inhibitions because the mode of activity of individual enzyme is different. In contrast to the AV, the absence of detectable renin inhibition or loss of inhibition by TO extracts at $0,60 \mathrm{~T} 2$, and 80 suggests possible antagonistic effects between the polyphenolic compounds. The results also suggest that unlike ACE inhibition the high contents of caffeic acid in TO extracts may not be an important factor for renin inhibition. Overall, renin inhibition was influenced by all the experimental factors, including sample variety, nitrogen fertilizer dose and time of fertilizer application. Table 3 shows that ACE and renin inhibitions were significantly affected by vegetable variety and the urea fertilizer dose as well as the interactions between these two variables. In contrast fertilizer application time influenced ACE-inhibitory properties but not renin. The statistical analysis also confirmed that the TO extracts had significantly $(\mathrm{P}<0.05)$ higher ACE inhibitory properties than AV

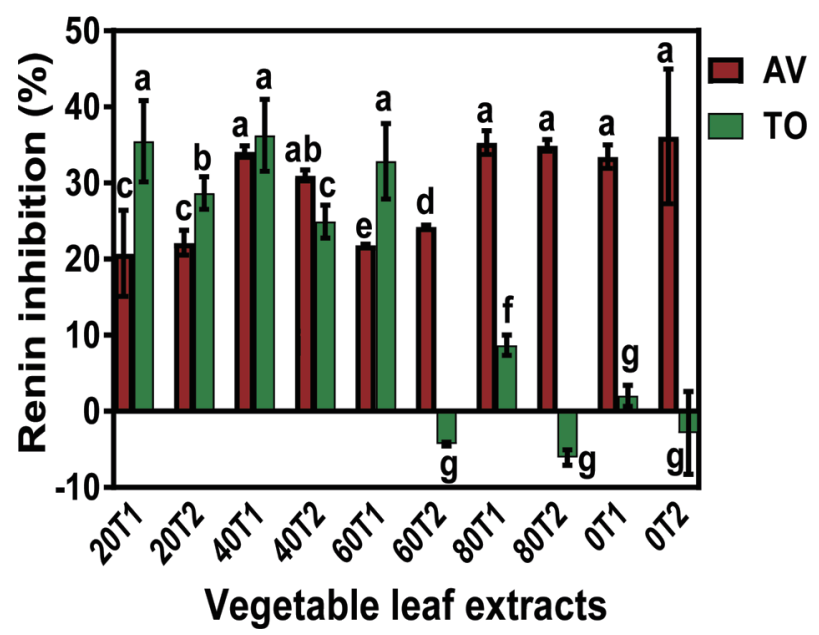

Figure 2. Renin-inhibitory activity of Amaranthusviridis (AV) and Telfariaoccidentalis (TO) polyphenol concentrates at $0.25 \mathrm{mg} / \mathrm{mL}$. 0-80 represent applied nitrogen fertilizer at planting (T1) or 1 week after seedling emergence (T2). Data are expressed as mean \pm standard deviation. Bars with different letters have significantly different $(P<0.05)$ mean values. 
extracts but the reverse was obtained for renin inhibition.

\subsection{In vivo reduction of blood pressure by vegetable extracts}

In order to test potential antihypertensive effects, two extracts from each plant variety (AV 40T1 and AV 80T1 or TO 40T1 and TO $60 \mathrm{~T} 2$ ) were orally administered to SHR. The choices were based on the need to determine whether in vitro ACE inhibition is a better prediction of antihypertensive effect than renin inhibition and vice versa. Thus AV 40T1 and 80T1 had two of the highest in vitro renin inhibitions but low ACE inhibition. In contrast, TO 40T1 and60T2 both had high (43-70\%) ACE inhibition but TO 60T2 had no detectable renin inhibition. Fig. 3A shows the SBP-lowering effects of $\mathrm{AV}$ and TO vegetable extracts in SHRs when compared to the antihypertensive drug, captopril. Single oral administration $(100 \mathrm{mg} / \mathrm{kg}$ body weight) of the vegetable extracts to SHRs resulted in varying but significant $(\mathrm{P}<0.05)$ changes in SBP up to the $24 \mathrm{~h}$ period when compared to the negative control (saline). A maximum SBP decrease $(-39.02 \pm 3.23 \mathrm{mmHg})$ was obtained for AV $40 \mathrm{~T} 1 \mathrm{after} 8 \mathrm{~h}$. In contrast the AV $80 \mathrm{~T} 1$ and TO extracts had lower SBP reductions with maximum values of approx. $-24 \mathrm{mmHg}$ after 4 or $8 \mathrm{~h}$. For all the samples, the SBP-lowering effect gradually but significantly $(\mathrm{P}<$ $0.05)$ diminished $24 \mathrm{~h}$ post-administration. The AV 40T1 had a significantly $(\mathrm{P}<0.05)$ stronger persistent effect with up to $\sim 11 \mathrm{mmHg}$ $\mathrm{SBP}$ reduction after $24 \mathrm{~h}$ when compared to the zero value for other samples. The results suggest that the AV 40T1 extract had a better resistance to enzymatic clearance from the blood circulatory system when compared to the remaining extracts. This pattern suggests that the extract was rapidly absorbed to produce maximum SBP decreases after $8 \mathrm{~h}$. Interestingly, the SBP-reducing effects did not have a strict, direct relationship with observed in vitro ACE and renin inhibitions. However, the AV 40T1 extract with reduced in vitro ACEinhibitory activity but increased renin inhibition produced most significant $(\mathrm{P}<0.05)$ SBP reductions, especially after $8 \mathrm{~h}$. Disparity between the in vivo and in vitro activities of these vegetable extracts could be due to the degradation of the structure of the compounds responsible for the inhibition of ACE and renin during passage along the digestive tract. It is also possible that the polyphenols are metabolized into compounds with weaker activities in the case of TO extracts or strong inhibitory compounds for the AV 40T1.Changes in the DBP were similar to those observed for the SBP, except that there were no significant differences up to $8 \mathrm{~h}$ after oral administration (Fig. 3B). However, the AV 40T1 extract showed significantly $(\mathrm{P}<0.05)$ longer persistence with DBP values of $-18 \mathrm{mmHg}$ after 12 and $24 \mathrm{~h}$ when compared to a range of -3 to $-12 \mathrm{mmHg}$ for the other extracts. The results obtained in this study correlate with several reports that indicate polyphenolic-rich extracts are able to delay the onset of hypertension and also regulate blood pressure (Sarr et al., 2006; Shaw et al. 2017). Taubert et al. (2003) reported that polyphenols from cocoa reduced blood pressure in elderly humans with mild isolated hypertension while Negishi et al.(2004) showed that black tea polyphenols reduced blood pressure in stroke-prone spontaneously hypertensive rats. Recently, a polyphenol concentrate from Ocimumgratissimum leaves had blood pressure-reducing effects after oral administration of $500 \mathrm{mg} / \mathrm{kg}$ body wt to SHR (Shaw et al. 2017). Since the antihypertensive effects of the AV and TO extracts were evident at $100 \mathrm{mg} / \mathrm{kg}$ bw, they can be considered to be more potent than O.gratissimum leaf extracts.

\subsection{Effect of vegetable extracts on MAP and $H R$}

Mean arterial pressure (MAP) is how well the body can process

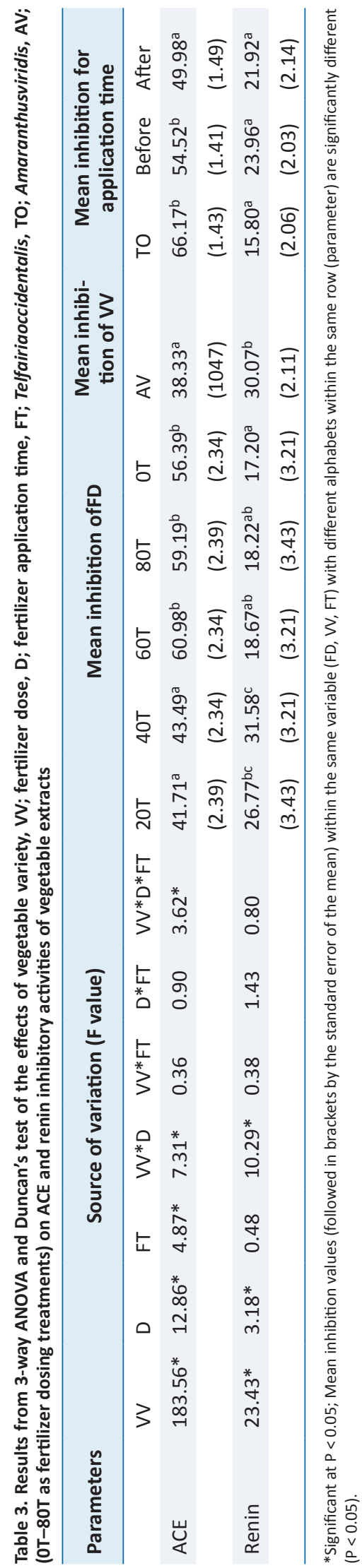



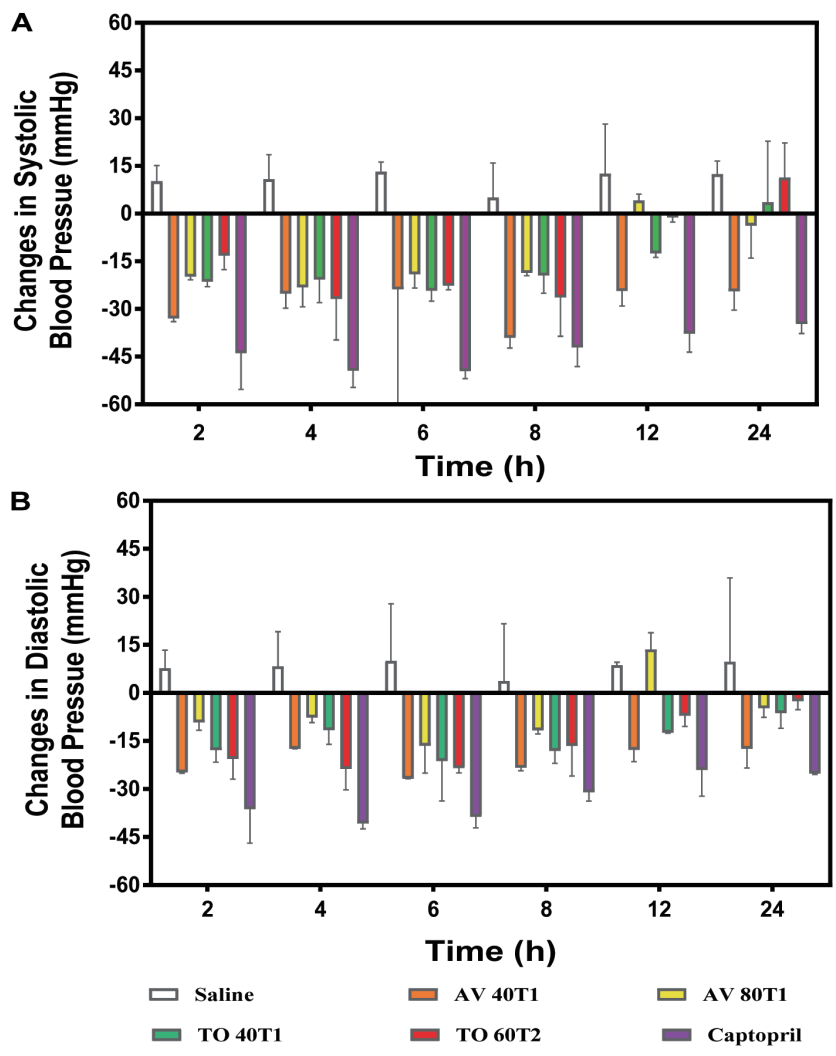

Figure 3. (A) Changes in Systolic and (B) Diastolic blood pressure ( $\mathrm{mmHg}$ ) of spontaneously hypertensive rats after oral administration of $100 \mathrm{mg} / \mathrm{kg}$ body weight polyphenol concentrates from Amaranthusviridis (AV 40T1 and AV 80T2), and Telfairiaoccidentalis f. treatments (TO 40T1 and TO 60T2). 40, 60, and 80 represent applied nitrogen fertilizer at planting (T1) or 1 week after seedling emergence (T2).

oxygenated blood that is delivered to the tissues and organs. It represents the mean blood pressure of an individual and is a measure of how well the heart can pump blood and the rate of flow of blood from the arteries(Henry et al., 2002). Therefore, high MAP values $(>140 \mathrm{mmHg}$ ) indicate a high workload for the heart and this may lead to heart attack, stroke and heart disease. When MAP is low $(<60 \mathrm{mmHg})$, this signifies that blood circulations to the necessary organs of the body are hindered and this can lead to shock. As shown in Fig. 4, single oral administration of the vegetable extracts to SHRs induced a reduction in mean arterial blood pressure (MAP). The AV 40T1 produced significantly better reductions in MAP especially after $6-8 \mathrm{~h}$ of oral administration and had the most persistent effect when compared to the other samples.

Heartrate (HR) is an important factor in the assessment of hypertension and it is the number of times the heart beats per minute. The vegetable extracts reduced HR of the SHRs with persistence of up12 and $24 \mathrm{~h}$ for AV samples. The AV 80T1 showed the most reductions with $107 \mathrm{ppm}$ after $8 \mathrm{~h}$ and -73 after $24 \mathrm{~h}$. An increase in heart beat rate is associated with increased blood pressure and possible risk of cardiovascular disease (James \& Friday, 2011; Reule \& PE, 2012). The result obtained revealed that the vegetable extracts reduce MAP and HR with AV and TO extracts having long lasting effects. The long-lasting effects of $\mathrm{AV}$ and $\mathrm{TO}$ on heart rate indicate that they may be effective antihypertensive agents or could function as ACE and/or renin inhibitors in hypertensive patients. The results are consistent with a recent report that

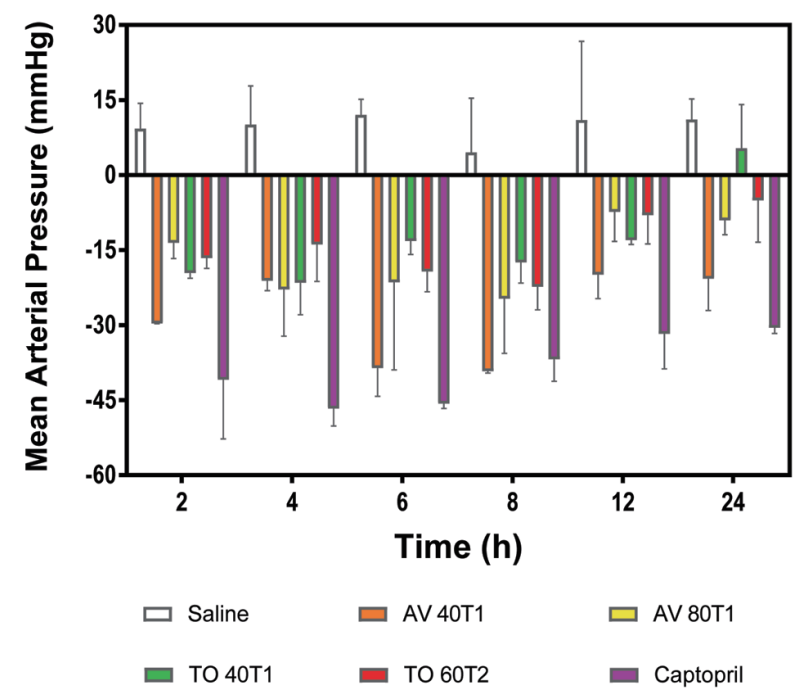

Figure 4. Changes in mean arterial blood pressure $(\mathrm{mmHg})$ of spontaneously hypertensive rats after oral administration of $100 \mathrm{mg} / \mathrm{kg}$ body weight polyphenol concentrates from Amaranthusviridis (AV 40T1 and AV 80T2), and Telfairiaoccidentalis f. treatments (TO $40 \mathrm{~T} 1$ and TO 60T2). 40, 60 , and 80 represent applied nitrogen fertilizer at planting (T1) or 1 week after seedling emergence (T2).

showed significant heart rate lowering effect after consumption of an anthocyanin-rich beverage by human volunteers over a $24-\mathrm{h}$ test period (Igwe et al., 2017).

\section{Conclusion}

The aqueous extracts of $\mathrm{AV}$ and TO leaves were composed mainly of polyphenols and possessed inhibitory activities against ACE and renin under in vitro conditions with $\mathrm{TO}$ extracts having higher

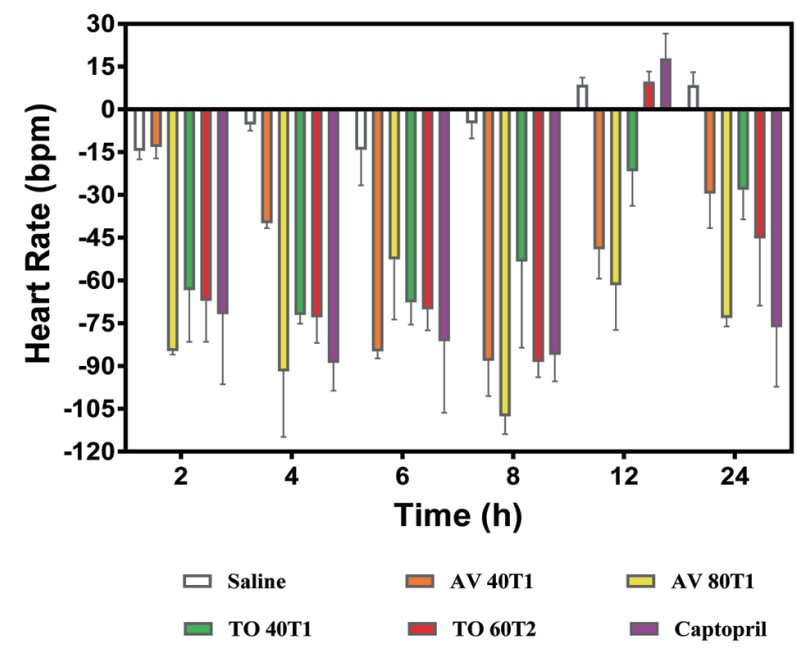

Figure 5. Changes in heart rate (bpm) of spontaneously hypertensive rats after oral administration of $100 \mathrm{mg} / \mathrm{kg}$ body weight polyphenol concentrates from Amaranthusviridis (AV 40T1 and AV 80T2), and Telfairiaoccidentalis f. treatments (TO 40T1 and TO 60T2). 40, 60, and 80 represent applied nitrogen fertilizer at planting (T1) or 1 week after seedling emergence (T2). 
ACE inhibitory activity than the AV. In contrast, the AV extracts had better renin inhibition than the TO. Oral administration to SHRs showed greater reductions in blood pressure and heart rate by the AV extract. There was no direct relationship between antihypertensive effects and in vitro enzyme (ACE and renin) inhibition patterns, which suggest that in vivo mode of action, may be different. Overall results suggest that these vegetable extracts could be used as functional food ingredients with therapeutic potential in the treatment or prevention of hypertension. However, future works that orally administer the main phenolic compounds (especially caffeic acid and rutin) to the SHRs will be required to confirm the blood pressure-reducing effects of the leaf polyphenol extracts.

AcknowledgmentsThis work was supported by a research grant (project 107983) from the Canadian International Development and Research Centre (IDRC) through the Canadian International Food Security Research Fund (CIFSRF) program. O.A. Olarewaju is a recipient of the University of Manitoba Graduate Fellowship for $\mathrm{PhD}$ studies.

\section{References}

Abassi, Z., Winaver, J., and Feuerstein, G.Z. (2009). The biochemical pharmacology of renin inhibitors:implications for translational medicine in hypertension, diabetic nephropathy and heart failure: expectations and reality. Biochem. Pharmacol. 78: 933-940.

Alu'datt, M.H., Alli, I., Ereifej, K., Alhamad, M., Al-Tawaha, A.R., and Rababah, T. (2010). Optimisation, characterisation and quantification of phenolic compounds in olive cake. Food Chem. 123: 117-122.

Aluko, R.E. (2015). Antihypertensive peptides from food proteins.Annu. Rev. Food Sci. Technol. 6: 235-262.

Blumentals, W.A., Brown, R.R., and Gomez-Caminero, A. (2003). Antihypertensive treatment and erectile dysfunction in a cohort of type II diabetes patients. Int. J. Impotence Res. 15: 314-317.

Chen, Z.Y., Peng, C., Jiao, R., Wong, Y.M., Yang, N., and Huang, Y. (2009). Anti-hypertensive nutraceuticals and functional foods. J. Agric. Food Chem. 57: 4485-4499.

Dong, J.Z., Gao, W.S., Lu, D.Y., and Wang, Y. (2011). Simultaneous extraction and analysis of four polyphenols from leaves of Lyciumbarbarum L. J. Food Biochem. 35: 914-931.

Farombi, E.O., and Owoeye, O. (2011). Antioxidative and chemopreventive properties of Vernoniaamygdalina and Garcinia biflavonoid. Int. J. Environ. Res. Public Health 8: 2533-2555.

Fogari, R., Zoppi, A., Poletti, L., Marasi, G., Mugellini, A., and Corradi, L. (2001). Sexual activity in hypertensive men treated with valsartan or carvediol: a crossover study. Am. J. Hypertens. 14: 27-31.

Ghiadoni, L., Magagna, A., Versari, D., Kardasz, I., Huang, Y., Taddei, S., and Salvetti, A. (2003). Different effect of antihypertensive drugs on conduit artery endothelial function. Hypertens 41: 1281-1286.

Girgih, A.T., Udenigwe, C.C., Li, H., Adebiyi, A.P., and Aluko, R.E. (2011). Kinetics of enzyme inhibition and antihypertensive effects of hemp seed (Cannabis sativa L.) protein hydrolysates. J. Am. Oil Chem. Soc. 88: 1767-1774.

Gunkel, A.R., Thurner, K.H., Kanonier, G., Sprinzl, G.M., and Thumfart, W.F. (1996). Angioneuroticedema as a reaction to angiotensin-converting enzyme inhibitors. Am. J. Otolaryngol. 17: 87-91.

Hellstrom, J.K., Shikov, A.N., Makarova, M.N., Pihlanto, A.M., Pozharitskaya, O.N., Ryhanen, E.-L., Kivijarvi, P., Makarov, V.G., and Mattila, P.H. (2010). Blood pressure-lowering properties of chokeberry(Aroniamitchurinii, var. Viking). J. Funct. Foods 2: 163-169.

Henry, J.B., Miller, M.C., Kelly, K.C., and Champney, D. (2002). Mean arterial pressure (MAP): An alternative and preferable measurement to systolic blood pressure (SBP) in patients for hypotension detection during hemapheresis. J. Clin. Apheresis 17: 55-64.

Hoff, J., and Singleton, K. (1977). A method for determination of tannins in foods by means of immobilized protein. J. Food Sci. 42: 1566-1569.

Holmquist, B., Bunning, P., and Riordan, J.F. (1979). A continuousspec- trophotometric assay for angiotensin converting enzyme. Anal. Biochem 95: 540-548.

Hussain, A.I., Anwar, F., Hussain Sherazi, S.T., and Przybylski, R. (2008). Chemical composition, antioxidant and antimicrobial activities of basil (Ocimumbasilicum) essential oils depends on seasonal variations. Food Chem. 108: 986-995.

Igwe, E.O., Charlton, K.E., Roodenrys, S., Kent, K., Fanning, K., and Netzel, M.E. (2017). Anthocyanin-rich plum juice reduces ambulatory blood pressure but not acute cognitive function in younger and older adults: a pilot crossover dose-timing study. Nutr. Res. 47: 28-43.

James, O., and Friday, E.A. (2011). Antihypertensive effect of methanol extract of Napoleonaimperialis(p. beauv) in adrenaline induced hypertensive albino rats. Int. J. Biochem. Res. Rev. 1: 47-57.

Kivimaki, A.S., Siltari, A., Ehlers, P.I., Korpela, R., and Vapaatalo, H. (2013). Lingonberry juice lowers blood pressureof spontaneously hypertensive rats (SHR). J. Funct. Foods 5: 1432-1440.

Lacaille-Dubois Franck, U., and Wagner, H. (2001). Search for potential angiotensin converting enzyme (ACE)-inhibitors from plants. Phytomed. 8: 47-52.

Li, H., and Aluko, R.E. (2010). Identification and inhibitory properties of multifunctional peptides from pea protein hydrolysateJ. Agric. Food Chem. 58: 11471-11476.

Malomo, S.A., Onuh, J.O., Girgih, A.T., and Aluko, R.E. (2015). Structural and antihypertensive properties of enzymatic hemp seed protein hydrolysates. Nutrients 7: 7616-7632.

Negishi, H., Xu, J.W., Ikeda, K., Njelekela, M., Nara, Y., and Yamori, Y. (2004). Black and green tea polyphenols attenuate blood pressure increases in stroke-prone spontaneously hypertensive rats. J. Nutr. 134: 38-42.

Nwanna, E.E., Ibukun, E.O., and Oboh, G. (2016). Effect of some tropical eggplant fruits (Solanum Spp) supplemented diet on diabetic neuropathy in male Wistar rats in- vivo.Funct. Foods Health Dis. n6: 661-676.

Oboh, G., Agunloye, O.M., Akinyemi, A.J., Ademiluyi, A.O., and Adefegha, S.A. (2013). Comparative study on the inhibitory effect of caffeic and chlorogenic acids on key enzymes linked to Alzheimer's disease and some pro-oxidant induced oxidative stress in rats' brain-in vitro. Neurochem. Res. 38: 413-419.

Oboh, G., Nwanna, E.E., and Elusiyan, C. (2006). Antioxidant and antimicrobial properties of Telfairiaoccidentalisleaf extracts. J. Pharmacol. Toxicol. 1: 167-175.

Oboh, G., and Rocha, J.B.T. (2007). Polyphenols in red pepper [Capsicum annuum var. aviculare (Tepin)] and their protective effect on some pro-oxidants induced lipid peroxidation in brain and liver. Eur. Food Res. Technol. 225: 239-247.

O'Keeffe, M.B., Norris, R., Alashi, M.A., Aluko, R.E., and FitzGerald, R.J. (2017). Peptide identification in a porcine gelatin prolyl endoproteinase hydrolysate with angiotensin converting enzyme (ACE) inhibitory and hypotensive activity. J. Funct. Foods 34: 77-88.

Pickering, T.G., Hall, J.E., Appel, L.J., Falkner, B.E., Graves, J., Hill, M.N., Jones, D.W., Kurtz, T., Sheps, S.G., and Roccella, E.J. (2005). Recommendations for blood pressure measurement in humans and experimental animals. Part 1: Blood pressure measurement in humans: A statement for professionals from the subcommittee of professional and public education of the American Heart Association Council on high blood pressure research. Hypertens 45: 142-161.

Reule, S., and Pe, D. (2012). Heart rate and blood pressure: any possible implications for management of hypertension? Curr. Hypertens. Reports 14: 478-484.

Sarr, M., Chataigneau, M., Martins, S., Schott, C., El Bedoui, J., Oak, M.H., Muller, B., and et al (2006). Red wine polyphenols prevent angiotensin II-induced hypertension and endothelial dysfunction in rats: Role of NADPH oxidase. Cardiovasc. Res. 71: 794-802.

Shaw, H.-M., Wu, J.-L., and Wang, M.-S. (2017). Antihypertensive effects of Ocimumgratissimum extract:Angiotensin-converting enzyme inhibitor in vitro and in vivoinvestigation. J. Funct. Foods 35: 68-73.

Taubert, D., Berkels, R., Roesen, R., and Klaus, W. (2003). Chocolate and blood pressure in elderly individuals with isolated systolic hypertension. J. Am. Med. Assoc. 290: 1029-1030.

Tenenbaum, A., Grossman, E., Shemesh, J., Fisman, E.Z., Nosrati, I., and Motro, M. (2000). Intermediatebut not low doses of aspirin can sup- 
press angiotensin-converting enzyme inhibitor-inducedcough. Am. J. Hypertens. 13: 776-782.

Udenigwe, C.C., Lin, Y.-S., Hou, W.-C., and Aluko, R.E. (2009). Kinetics of the inhibition of renin and angiotensin l-converting enzyme by flaxseed protein hydrolysate fractions. J. Funct. Foods 1: 199-207.
Wagner, H., and Elbl, G. (1992). ACE-inhibitory procyanidins from Lespedeza capitata. Planta Medica 58: 297.

WHO. (2013). World Health Organization.A Global Brief on Hypertension: Silent Killer, Global Public Health Crisis. WHO/DCO/WHD/2013. 2nd ed. Geneva, Switzerland. 